\title{
ON COLLECTION OF PREDATORY THRIPS (INSECTA: THYSANOPTERA) IN WHEAT FIELDS
}

\author{
Behzad Miria, Majid Mirab-balou ${ }^{b^{*}}$ and Naser Moeini-Naghadeh ${ }^{a}$
}

\author{
${ }^{a}$ Department of Plant Protection, College of Agriculture, Razi University, Kermanshah, Iran \\ ${ }^{b}$ Department of Plant Protection, College of Agriculture, Ilam University, Ilam, Iran \\ *Corresponding author. Email: m.mirabbalou@ilam.ac.ir
}

\author{
Article history \\ Received: 10 April 2020; \\ accepted 3 August 2020
}

\section{Keywords:}

Thysanoptera; wheat; temperature; Ilam

\begin{abstract}
Some thrips species are known as predators of eggs, exist as the inactive stages of mites, and can be tiny, especially phytophagous thrips. This study aimed at evaluating the population fluctuation and species diversity of predatory thrips in wheat fields of Eyvan county (Ilam province, Iran) in the year 2016. Thrips specimens were collected and identified by weekly sampling during wheat growth stages (from early April to late June). Wheat bushes were shaken on a white dish. Finally, microscopic slides were prepared and all samples were enumerated. The population fluctuation of predatory thrips was calculated. In this study, six species of predatory thrips belonging to three genera were identified. Amongst them, Aeolothrips intermedius Bagnall (family Aeolothripidae) was the dominant species in both irrigated and rainfed wheat fields accounting for $72.43 \%$ and $50.85 \%$ of all species, respectively. Biodiversity indices were calculated using the number of species and their relative abundance. Shannon diversity, Simpson's, Margalef's and species richness indices were $1.76,0.86,1.25$ and 1 , respectively. The highest biodiversity was in rainfed fields and during the wheat flowering stage, and the highest Shannon-Wiener evenness index was also in rainfed fields and at the ripening stage. The richness of thrips in rainfed wheat fields during the stem elongation stage was higher than in other wheat stages. Correlation of the density of predatory thrips with temperature and humidity showed a significantly positive correlation with temperature.
\end{abstract}

\section{INTRODUCTION}

Wheat (Triticum aestivum $\mathrm{L}$.) is one of the most important cultivated crops in the world. During a short period of growth, wheat hosts many insects and mites (Andjus 1998). In Iran, several species of thrips have been collected and reported in wheat and barley fields, most of them being phytophagous and a few predatory (Alavi et al. 2007). The most common phytophagous thrips observed on wheat in Iran is the wheat thrips, Haplothrips tritici (Kurdjumov) (Alavi et al. 2007; Mirab-balou 2011; Miri et al. 2017). H. tritici is the dominant thrips species on wheat and barley in the world (Tunç 1992; Lewis 1997; Özsisli 2011).

Thrips constitute an economically important group of minute insects with their body length ranging from 0.5-15 mm (Mound and Marullo 1998). Unlike phytophagous and fungal feeder species, some thrips species are predatory and therefore serve as bio-control agents of arthropod pests (Cox et al. 2006; Morse and Hoddle 2006). Most predatory thrips belong to the following genera (zur Strassen 1995): Apterygothrips Priesner, Aleurodothrips Franklin, Aeolothrips Haliday, Podothrips Hood, Leptothrips Hood, Karnyothrips (Watson), Haplothrips Amyot and Serville, Franklinothrips Back, Scolothrips Hinds, and Xylaplothrips Priesner.
Predatory thrips feed on eggs or on prey in slow-moving stages, including phytophagous mites, true bugs, aphids and phytophagous thrips (Palmer et al. 1992). Although many species of thrips have been known as predators of mites and eggs of some small insects, due to the importance of more phytophagous thrips, predators have not been paid much attention (zur Strassen 1995). However, some of them, including the genus Scolothrips, have always been of particular importance because of their specific spread and nutrition, as they feed on tetranychid mites (Chazau 1985).

A number of researchers have recorded the occurrence of diverse species of predatory thrips from different parts of the world (Okajima et al. 1992; Lewis 1997; Mound and Reynaud 2005; Varatharajan et al. 2018). Some predatory thrips, such as Haplothrips victoriensis Bagnall, feed only on phytophagous mite eggs in field conditions (Chazau 1985); and Aleurodothrips fasciapennis Franklin is the most effective predator of the citrus red scale (Aonidiella aurantii) in southern China and Australia (Tian and Chen 1991). There are currently many studies on the use of Scolothrips longicornis Priesner to control spider mites in greenhouses (Selhorst et al. 1991), and three species of Franklinothrips are also used in European greenhouses as biological control agents (Mound and Reynaud 2005).

So far, several predatory thrips from wheat and barley 
fields of Iran have been reported, including Aeolothrips collaris, A. mongolicus and A. tenuicornis in Golestan province (Alavi et al. 2007), A. intermedius and Haplothrips subtilissimus in Ardabil province (Fathi et al. 2013), and A. intermedius and S. longicornis in Hamedan province (Mirab-balou et al. 2014). Mirab-balou (2011) has also collected and identified various predatory species of Aeolothrips, Haplothrips and Scolothrips from most wheat and barley fields of different provinces of Iran. In Lithuania and Serbia, A. intermedius has been reported as the only predator species in winter wheat fields (Andjus 1998; Šmatas et al. 2013). The species has been introduced as one of the most abundant species in the wheat and barley fields of Serbia.

Since there has been no comprehensive study of predatory thrips in Iran previously, the present study was conducted to identify, determine biodiversity and monitor population fluctuations of predatory thrips in the wheat fields of Ilam province (west of Iran).

\section{MATERIALS AND METHODS}

\section{Thrips collection}

Investigations were carried out in 12 rainfed wheat (RW) and irrigated wheat (IW) fields in Sarab, Eyvan, Khoran, Kalan, Zarneh, and Chehel Zari in Eyvan county, Ilam province, west of Iran. Thrips specimens were collected every week during different growth stages of wheat (i.e. stem elongation, booting, heading, flowering, early grain milk, late grain milk, grain dough, and ripening) (Zadoks et al. 1974) from April to the end of June in the year 2016. The pattern for sampling was $\mathrm{W}$-shaped movement in the fields. Specimens were collected by beating wheat plants (20 plants in each field) onto a white dish tray, and extracted from soil using a Berlese funnel during the plant elongation stage. Thrips were then individually collected using a fine paint brush, transferred into vials filled with $75 \%$ ethanol alcohol, and total numbers were recorded.

\section{Thrips identification}

The method for preparing and mounting thrips on slides for microscopic identification followed Mirab-balou and Chen (2010). Where more than 100 thrips were collected, only 100 specimens were mounted. Adults of thrips were identified to species, whereas larvae species were not identified, because their determination is impossible.

\section{Data analysis}

Thrips diversity (Shannon index), dominance (Simpson's index), and evenness (E index) were calculated using the PAST software (Hammer et al. 2001). The
Shannon-Wiener index was calculated by the following formula (Shannon and Weaver 1949):

$$
H^{\prime}=-\sum_{i=1}^{s} \frac{n_{i}}{N} \ln \frac{n_{i}}{N}
$$

where $n_{i}$ is the number of specimens of $i$-species per sample, $N$ is the number of all species per sample, and $\mathrm{s}$ is the number of species in the community.

Species richness was estimated using Margalef's richness index. Species richness is the number of species recorded. which does not take into account relative abundances. Instead, it includes the sum of individuals recorded for all the species in a specific sample plot:

$$
D_{m g}=S-1 / \operatorname{Ln} N,
$$

where $D_{m g}$ is Margalef's richness index, $S$ is the number of species recorded, and $N$ is the total number of individuals in the sample (Margalef 1958).

The domination coefficient informs what percentage out of the total amount of collected specimens for a given area is constituted by specimens of a particular species. It was calculated using the formula developed by Kasprzak and Niedbala (1981):

$$
D_{i}=\frac{n_{i}}{N} 100 \% \text {, }
$$

where $D i$ is the dominance of a particular species, $n_{i}$ is the numerousness of a particular species, and $\mathrm{N}$ is the total number of all species. The analyses were done using SPSS version 11.

In order to determine the relationship of the density of predatory thrips with temperature and humidity, these data $(T$ and $H$ ) were used from Weather Station located in Ilam province. For this purpose, correlation analysis between density of predatory thrips (dependent variable), temperature and humidity (independent variables) was performed, and $\mathrm{b}, R^{2}$ and $p$-value were determined for each relationship by SPSS software.

\section{RESULTS AND DISCUSSION}

From 896 predatory thrips specimens collected (468 and 428 specimens from RW and IW, respectively), six species belonging to three genera were identified: Aeolothrips albicinctus Haliday, A. collaris Priesner and A. intermedius Bagnall (family Aeolothripidae), Scolothrips longicornis Priesner (family Thripidae), Haplothrips globiceps Bagnall and H. subtilissimus (Haliday) (Phlaeothripidae) (Figure 1). Amongst them, A. intermedius was the dominant species in both IW and RW with $72.43 \%$ and $50.85 \%$, respectively (Figure 2). In addition, $A$. albicinctus and $H$. subtilissimus were collected accidentally in very low numbers (less than 
10 specimens). Aeolothrips species were active in the fields from the beginning of wheat growth until the end of harvest, whereas a few specimens of $S$. longicornis were collected at the end of wheat growth stages.

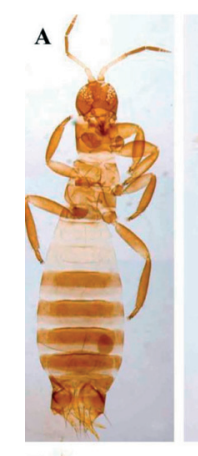

D

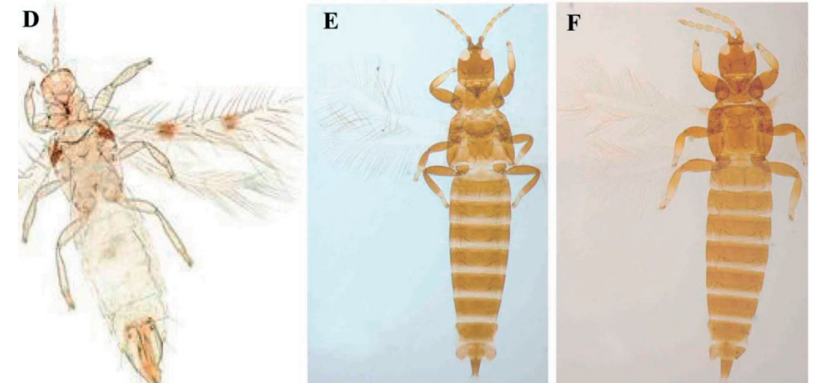

Figure 1. Predatory thrips species (adult, female): (A) A. albicinctus, (B) A. collaris, (C) A. intermedius, (D) S. longicornis, (E) H. globiceps, (F) H. subtilissimus.

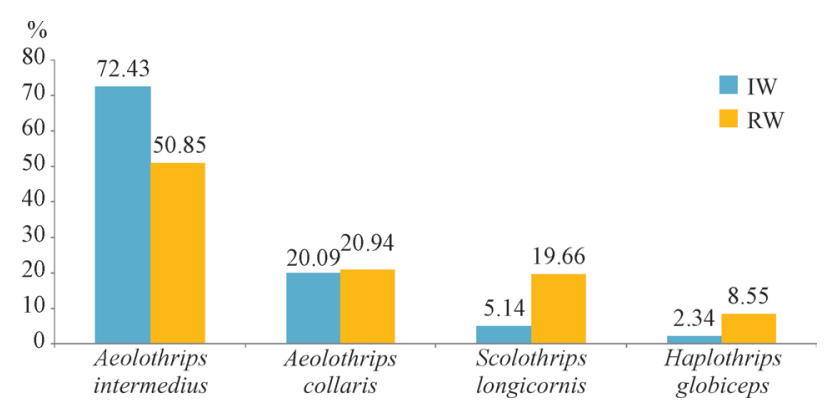

Figure 2. The frequency of predatory thrips in wheat fields of Eyvan county (Ilam province, Iran).

Key to predatory thrips on wheat fields in Ilam province, Iran

A. Forewings surface smooth and without veins and setae; terminal abdominal segment tube-like; female without external ovipositor

...(Suborder Tubulifera) Phlaeothripidae

- Pronotal anteromarginal setae well developed, almost half the length of epimeral setae or longer, usually expanded at apex.

Haplothrips subtilissimus

- Pronotal anteromarginal setae reduced, much shorter than half the length of epimeral setae, usually pointed at apex.....

Haplothrips globiceps

a. Forewings surface with microtrichia and with veins and setae; terminal abdominal segment not tubular; female with saw-like ovipositor

(Suborder Terebrantia) B

B. Ovipositor curved usually downward; antennae 6- to 9-segmented; forewings pointed at apex

(Thripidae)

- Pronotum with six pairs of very long setae; forewing with sub-basal dark band fully including costal margin of wing; pterothorax not shaded laterally, abdominal tergites yellow, metascutum yellow

Scolothrips longicornis

b. Ovipositor curved upwards; antennae 9-segmented; forewings relatively broad, with apex rounded.

(Aeolothripidae)

- Body bicolour, mostly dark, but segments II-III white; first abdominal tergite with close-set transverse striae

Aeolothrips albicinctus

- Body and legs dark brown, pronotum pale yellow; antennae dark brown, except antennal segment III yellow with apex brown, segment II yellowish in apical half

Aeolothrips collaris

- Body brownish black to black; antennae brown, segment III whitish with dark brown in apical part

Aeolothrips intermedius

Aeolothrips intermedius is predatory in the larval stage, but in the adult stage it also feeds on pollen in addition to predation (Marullo 2004). In the wheat fields of Eyvan city, there are different phytophagous thrips; amongst them the wheat thrips (Haplothrips tritici) has high population abundance during wheat growth stages (Miri et al. 2017). Despite the presence of predatory thrips in these fields, they are not able to reduce the population of wheat thrips (Figures 3 and 4), one of the reasons being the generality of these predatory thrips.

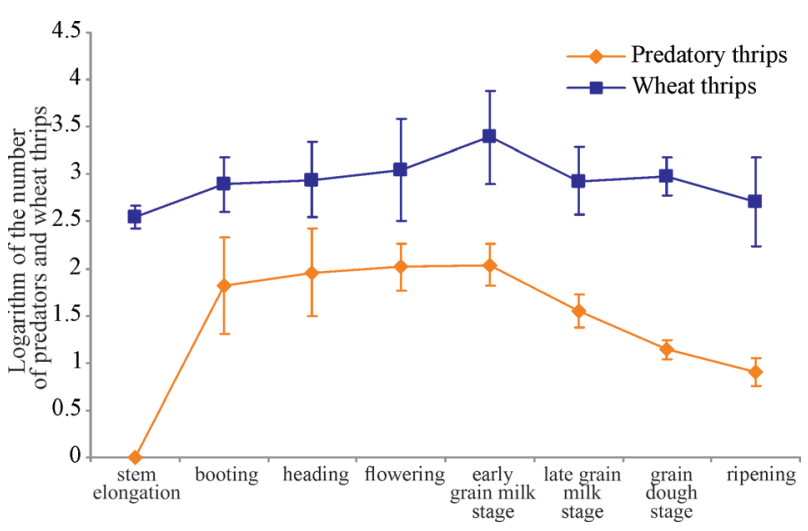

Figure 3. Population fluctuation of predatory thrips and wheat thrips in IW, Eyvan county (Ilam province, Iran). 


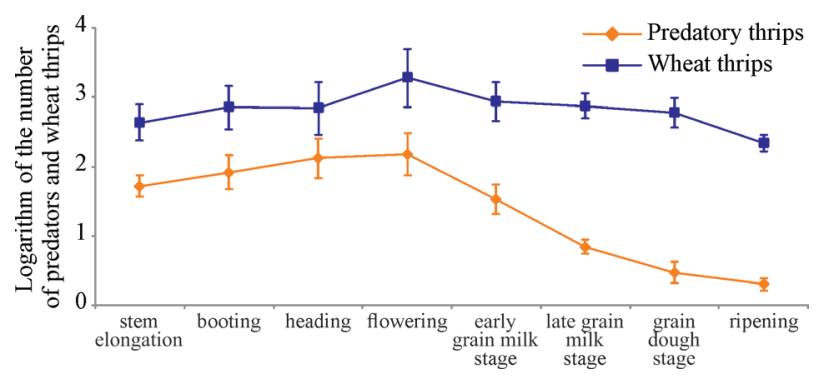

Figure 4. Population fluctuation of predatory thrips and wheat thrips in RW, Eyvan county (Ilam province, Iran).

There were no predatory thrips in IW fields at the beginning of spring (early April), i.e. during early stages of wheat growth (Figure 5). As temperature rose, thrips were observed in high numbers at the early grain milk stage. However, in RW predatory thrips were observed in the fields from the beginning of the stem elongation stage in spring, with high numbers during the flowering stage (Figure 5).

The relationship between population density of predatory thrips and temperature was significant and positive in both IW and RW (Table 1). It means that the density of predatory thrips is positively dependent on temperature. In other words, the number of predatory thrips increases when temperature increases.

Table 1. Correlation of the density of predatory thrips with temperature and humidity in IW and RW.

\begin{tabular}{|l|c|c|c|c|}
\hline Climatic factors & Fields & $p$-value & $\mathrm{R}^{2}$ & $\mathrm{~b}$ \\
\hline \multirow{3}{*}{ Temperature } & IW & $0.03^{* *}$ & 0.61 & + \\
\cline { 2 - 5 } & RW & $0.04^{* *}$ & 0.52 & + \\
\hline \multirow{2}{*}{ Humidity } & IW & $0.06^{\mathrm{ns}}$ & 0.52 & - \\
\cline { 2 - 5 } & RW & $0.07^{\mathrm{ns}}$ & 0.44 & - \\
\hline
\end{tabular}
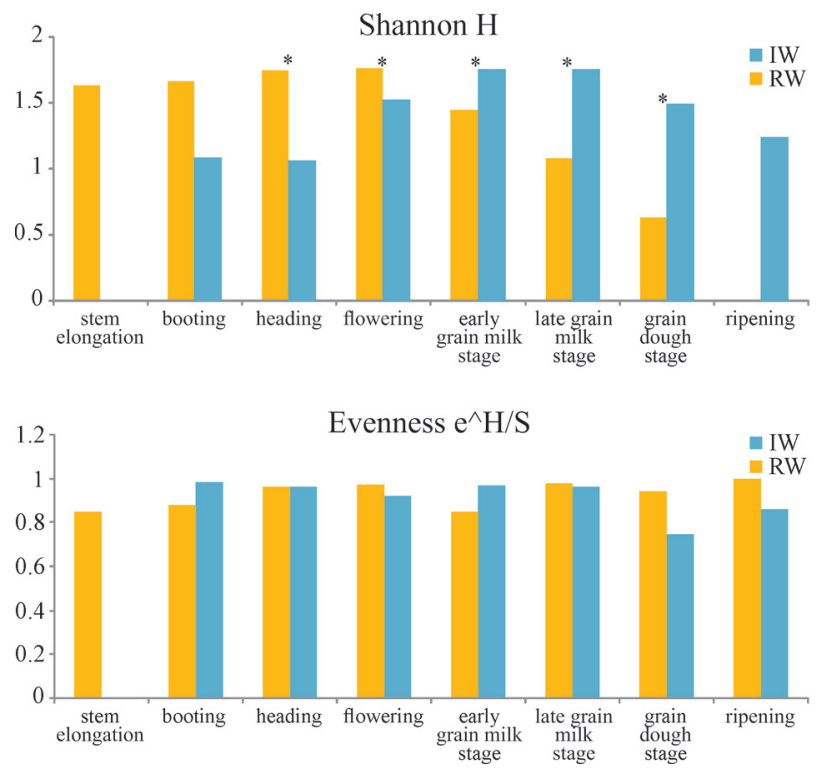

Biodiversity indices were calculated using the number of species and their relative abundance. The results showed that all diversity indices were higher in RW than IW, and the highest species diversity based on the Shannon-Wiener index was related to the wheat flowering stage with a value of 1.76; the highest value of Simpson's index (0.86) was also related to the wheat flowering stage, and the highest value of Margalef's species richness index was 1.25 and it related to wheat stem elongation. The richness of thrips in RW during the stem elongation stage was higher than in other wheat stages (Figure 5). In this study, the values obtained for both Shannon-Wiener and Simpson indices at wheat growth stages indicate the diversity of desirable species at the flowering stage in RW. In addition, the highest richness index was related to RW at wheat ripening stage, indicating the stability of predatory thrips at this stage of wheat growth.

The utility of predatory thrips as effective bio-control agents has been well documented, and different researchers have successfully demonstrated the application of predatory thrips as agents of biological control. For example, Aeolothrips intermedius was used along with the anthocorid, Orius niger (Wolff) for the control of field populations of Thrips tabaci Lindeman and Frankliniella occidentalis (Pergande) (Fathi et al. 2008; Blaeser et al. 2004). The family Aeolothripidae under the suborder Terebrantia includes only about $5 \%$ of all described species, i.e. with 194 extant species in 23 genera worldwide (ThripsWiki 2020), and they exhibit a wide range of feeding diversity, from obligate phytophagic feeding to facultative predation on small arthropods that live in flowers (Mound 1997; Mound and Marullo 1998). The results of a study by Fathi et al. (2013) showed that $A$. intermedius in high densities
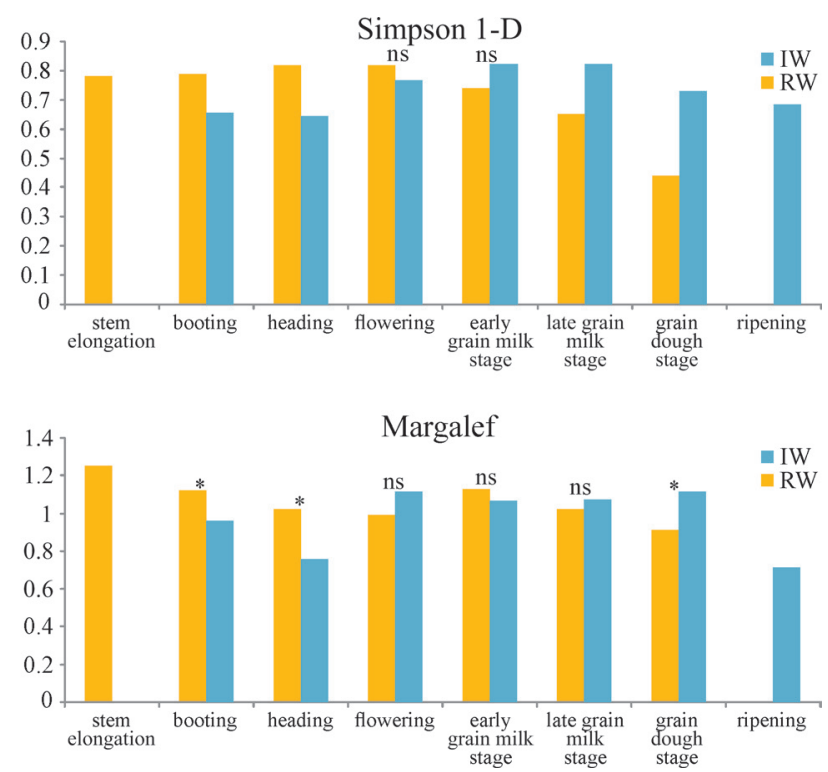

Figure 5. The numerical value of diversity indices in each of the fields, according to the wheat growth stages. $\left({ }^{*} p<0.05\right.$ and ns $=$ no significant $)$. 
was the dominant predator among natural enemies of wheat thrips. This predatory thrips was also a dominant predator on maple trees in the forests of Ilam province, Iran (Mirab-balou 2016). The results of a study on bean thrips in Hamedan province (west of Iran) showed A. intermedius and S. longicornis had the highest populations among predatory thrips (Mirab-balou and Miri 2016).

Among phlaeothripids of the suborder Tubulifera, majorities are fungal feeders and the rest constitute plant sap sucking forms, a portion of which predate on mites, thrips and coccids (Mound 1997). In this study, two predatory thrips $H$. globiceps and $H$. subtilissimus were collected in wheat fields. These two species are predators on mites and lepidopteran eggs, as well as the immature stages of scale insects and whiteflies (Mound 1997). The latter species were also reported as predators of armoured scale insects (Palmer and Mound 1990).

\section{ACKNOWLEDGMENTS}

We are grateful to anonymous reviewers for useful comments. This paper is extracted from part of the MSc thesis of the senior author, who was financially supported by research vice-chancellor of Razi University, Kermanshah, Iran.

\section{DISCLOSURE STATEMENT}

No potential conflict of interest was reported by the authors.

\section{REFERENCES}

Alavi, J., R. zur Strassen, and N. Bagheerani. 2007. Thrips (Thysanoptera) Species associated with wheat and barley in Golestan province, Iran. Journal of Entomological Society of Iran 27: 1-28.

Andjus, L. 1998. Thrips species of wheat and barley in Yugoslavia. In Proceedings $6^{\text {th }}$ International Symposium on Thysanoptera, Antalya, 1-5.

Blaeser, P., C. Sengonca, and T. Zegula. 2004. The potential use of different predatory bug species in the biological control of Frankliniella occidentalis (Pergande) (Thysanoptera: Thripidae). Journal of Pest Science 77: 211-9.

Chazau, J. 1985. Predator insects. In World Crop Pest, Spider Mites: Their Biology, Natural Enemies and Control, edited by Helle, W. and M. W. Sabilis, 211-246. Amsterdam: Elsevier Publ.

Cox, P. D., L. Matthews, R. J. Jacobson, R. Cannon, A. MacLeod, and K. F. A. Walters. 2006. Potential for the use of biological agents for the control of Thrips palmi (Thysanoptera: Thripidae) outbreaks. Biocontrol Science and Technology 16: 871-891.

Fathi, S. A. A., A. Asghar, and M. Sedghi. 2008. Interaction of Aeolothrips intermedius and Orius niger in controlling Thrips tabaci on Potato. International Journal of Agriculture and Biology 10: 521-525.

Fathi, S. A. A., G. Nouri-Ganbalani, and E. Belali-Mashkour. 2013. Evaluation of two wheat cropping systems for enhancing biological control of the wheat thrips, Haplothrips tritici (Thys.: Phlaeothripidae). Journal of Entomological Society of Iran 33: 49-58.

Hammer, Ø., D. A. T. Harper, and P. D. Ryan. 2001. PASTPalaeontological Statistics software package for education and data analysis. Palaeontologia Electronica 4: 1-9.

Kasprzak, K., and W. Niedbała. 1981. Biocenotic indicators in quantitative research. In Methods Applied in Soil Zoology, edited by Górny M. and L. Grüm, 397-416. Warszawa: PWN.

Lewis, T. 1997. Thrips as Crop Pests. Wallingford, U. K: CAB International, $349 \mathrm{pp}$.

Margalef, M. 1958. Information theory in ecology. General Systematics 3: 36-71.

Marullo, R. 2004. Host-plant range and relationships in the Italian thrips fauna. Acta Phytopathologica et Entomologica Hungarica 39: 243-254.

Mirab-balou, M. 2011. A systematic study of Thysanoptera in Iran (Hexapoda: Insecta). Ph.D. thesis, College of Agriculture and Biotechnology, 643 pp. Zhejiang University, Hangzhou, China. Mirab-balou, M. 2016. Identification of natural enemies of maple thrips, Taeniothrips inconsequens (Uzel) (Thy.: Thripidae) in Ilam Province. Plant Pest Research 6: 83-87.

Mirab-balou, M., and X. X. Chen. 2010. A new method for preparing and mounting thrips for microscopic examination. Journal of Environmental Entomology 32: $115-121$.

Mirab-balou, M., and B. Miri. 2016. Thrips species (Insecta: Thysanoptera) associated with bean (Phaseolus vulgaris L.) in Hamedan province, Iran. The $3^{\text {th }}$ congress of the development and promotion of agricultural sciences, natural resources and the environment, Tehran, Iran, $3 \mathrm{pp}$.

Mirab-balou, M., A. Fazelie, and Z. Maryami. 2014. Study of thrips species associated with wheat crops in Hamedan Province. $7^{\text {th }}$ Congress of Advances in Agriculture Research, Kurdistan, Iran: 121-123.

Miri, B., N. Moeini-Naghadeh, and M. Mirab-balou. 2017. Population fluctuations and spatial distribution of wheat thrips (Haplothrips tritici) in wheat fields of Eyvan city (Ilam Province). Plant Pest Research 7: 67-76.

Morse, J. G., and M. S. Hoddle. 2006. Invasion biology of thrips. Annual Review of Entomology 51: 67-89.

Mound, L. A. 1997. Biological diversity. In Thrips as Crop 
Pests, edited by Lewis T., 197-215. Wallingford: CAB International.

Mound, L. A., and R. Marullo. 1998. Biology and identification of Aeolothripidae (Thysanoptera) in Australia. Invertebrate Taxonomy 12: 929-950.

Mound, L. A., and P. Raynaud. 2005. Franklinothrips; a pantropical Thysanoptera genus of ant-mimicking obligate predators (Aeolothripidae). Zootaxa 864: 1-16.

Okajima, S., Y. Hirose, H. Kajita, M. Takagi, B. Napompeth, and S. Buranapanichpan. 1992. Thrips on fruit vegetables in South east Asia. Applied Entomology and Zoology 27: 300-303.

Özsisli, T. 2011. Population densities of wheat thrips, Haplothrips tritici Kurdjumov (Thysanoptera: Phlaeothripidae), on different wheat and barley cultivars in the province of Kahramanmaras, Turkey. African Journal of Biotechnology 10: 7063-7070.

Palmer, J. M., and L. A. Mound. 1990. Thysanoptera. In The armoured scale insects, their biology, natural enemies and control, edited by Rosen, D., 67-75. Amsterdam (The Netherlands): Elsevier.

Palmer, J. M., L. A. Mound, and G. J. Heaumane. 1992. Guides to insects of importance to man. II. Thysanoptera, 75 pp. London: CAB International Institute of Entomology and British Museum (Natural History).

Selhorst, T., D. Sondyerath, and S. Weigand. 1991. A model describing the predator-prey interaction between $\mathrm{Scol}$ othrips longicornis and Tetranychus cinnabarinus based upon the Leslie theory. Ecology Model 54: 123-136.
Shannon, C. E., and W. Weaver. 1949. The mathematical theory of communication, $350 \mathrm{pp}$. University of Illinois Press.

Šmatas, R., K. Tamošiūnas, and V. Danytė. 2013. Diversity and sex ratio of thrips (Thysanoptera) species in winter wheat in Lithuania. Zemdirbyste-Agriculture 100: 289-292.

ThripsWiki. 2020. ThripsWiki-providing information on the World's thrips. Available from: http://thrips.info/wiki/ [Accessed 05 March 2020].

Tian, M. Y., and S. J. Chen. 1991. Observations on the biology of A. fasciapennis (Franklin), a predator of diaspid scales on citrus. In Proceedings of the 1991 National Symposium on Biological Control, edited by Ye, Z. C., R. Wang, and Q. Zhang, 76. Beijing: Chinese Academy of Science Biological Control Laboratory.

Tunç, I. 1992. Studies on the Thysanoptera of Antalya, V. Phlaeothripidae Uzel with an overall account. Turkish Journal of Entomology 16: 135-146.

Varatharajan, R., K. Nishikanta Singh, and R. R. Rachana. 2018. On the collections of predatory thrips (Insecta: Thysanoptera) from NE India. Journal of Biological Control 32: 8-13.

Zadoks, J. C., T. T. Chang, and C. F. Konzak. 1974. A decimal code for the growth stages of cereals. Weed Research 14: 415-421.

zur Strassen, R. 1995. Binomial data predaceous thrips. In Thrips Biology and Management edited by Parker, B. L., M. Skinner, and T. S. Lewis, 326-328. New York: Plenum Press. 